\title{
Policy Issues in Meeting Rice Farmers Agricultural Information Needs in Niger State
}

Tologbonse, D $^{1}$; O.Fashola ${ }^{2,}$ and M. Obadiah ${ }^{1 .}$

1. National Agricultural Extension \& Research Liaison Services

Ahmadu Bello University

Middle Belt Zonal Office, Box 770, Bida

Niger State

Email: deletologbonse@yahoo.com

2. International Institute for Tropical Agriculture

P.M.B, 5320, Ibadan

Oyo State

\begin{abstract}
The study aimed at assessing rice farmers agricultural information needs and the constraints faced in sourcing for information. Primary data were collected through field survey from 5 out of 8 Local Government Areas (LGA) in Zone 1 of Niger State Agricultural development Programme (NSADP) where lowland rice is a major crop. From each of the LGAs, two villages were randomly selected and one farmers group were randomly selected per village. From a total of 234 farmers a total of 186 farmers were interviewed representing $80 \%$ of the population. Result of data analysis, revealed that about $73 \%$ of the respondents usually seek for information from extension agents.
\end{abstract}

Majority $(72.7 \%)$ of farmers seek for information from the extension agents and $37 \%$ preferred that information be packaged as audio cassette. Major constraints include lack of funds to acquire information (54.3\%) and language barrier (50.5\%). The result of the study also indicates a significant relationship between information type and preferred information package $\left(X^{2}=27.96 ; p<0.05\right)$, readiness to pay for information package $\left(X^{2}=67.45 ; p<05\right)$ and constraint $\left(\left(X^{2}=33.28 ; p<\right.\right.$ $05)$. No significant relationship between information type and, age $\left(X^{2}\right.$ $=0.001 ; p<05)$, educational level $\left(X^{2}=1.59 ; p<05\right)$, sex $\left(X^{2}=1.31 ; p<\right.$ 05 ) and ownership of telephone $\left(X^{2}=0.48 ; p<05\right)$.

The data generated will assist in the implementation of the Nigerian Question and Answer Service (NAQAS) under the auspices of National Agricultural Extension and Research Liaison Services, supported by the Technical Centre for Agricultural and Rural Cooperation in providing information in all aspects of agriculture on demand to farmers.

\section{INTRODUCTION}

Information is regarded as one of the most valuable resources in agricultural and rural development programmes (Carter, 1999; Meyer 2003; Morrow et al, 2002) It is also regarded as an important input in agriculture (Tripp, 2006). Nigerian farmers are reported not to feel the impact of agricultural innovations mainly because they have no 
access to such vital information or due to poor dissemination(Ozowa, 1995; Tripp, 2006). The information usually provided, is reported to be focused mainly on policy makers, researchers, students and those who manage policy decisions with little or no attention paid to the information needs of farmers who are the targeted beneficiaries of the policy decisions (Ozowa, 1995; Oguya, 2007; Omenesa, 2007)

Even though small scale Farmers' accessibility to agricultural innovations is often limited by unfavorable economic, socio-cultural and institutional conditions, they have achieved some level of efficiency through deployment of their indigenous knowledge. If provided with the right inputs, feasible technology and relevant information which they actually need, they are capable of transforming traditional agriculture.

Ozowa (1995)opined that no one can categorically claim to know all the information needs of Farmers, especially in an information dependent sector like agriculture where there are new and rather complex problems facing farmers every day. The information needs of Nigerian farmers is therefore likely to vary from one community to another due to various factors.

A better understanding of the specific needs of farmers in each State and community of Nigeria is needed. This approach will lead to site specific information and will cater for the specific needs of the farmers in that locality precisely.

In order to meet the specific needs of stakeholders in agriculture in Nigeria, the Technical Centre for Agricultural and Rural Cooperation (CTA) developed and introduced the Nigeria Agricultural Question and Answer Service (NAQAS), under the auspices of National Agricultural Extension and Research Liaison Services (NAERLS) while the National Agricultural Research Institutes (NARIs) partner to provide information in all aspects of agriculture on demand. The service is supported by the Technical Centre for Agricultural and Rural Cooperation (CTA). However, reports from NAQAS stakeholders meetings revealed that farmers derive the least benefits from NAQAS service while other beneficiaries such as researchers, lecturers, students and agro-processors make better use of the service (Oguya, 2007; Omenesa, 2007) This was attributed to the fact that the farmers are probably unaware of the services and are therefore not able to use it. However, in other to serve the clienteles better, particularly the farmers who are the main key stakeholders in rural development, the need to know farmers information needs cannot be over emphasized.

This is in other to prepare fully for the service to serve the farmers better. Previous study in Nigeria was a National survey with only 175 respondents (Omenesa, 2007) with no specific one on any locality or State in Nigeria since farmers information needs is likely to vary from one State/community to another due to various factors.

The study was therefore aimed at assessing Niger State lowland rice farmers agricultural information needs and the constraints faced in sourcing for information.

The specific objectives of the study were to:

i. describe the socio-economic characteristics of the respondents,

ii. describe the type of Information needed,

iii. ascertain sources where they usually seek for Information and

iv. describe the nature of constraints the farmers faced

v. ascertain the relationship between information type and other variables 


\section{METHODOLOGY}

Niger state is one of the states in the Middle Belt region of Nigeria. The State is one of the largest States in Nigeria and has a land area of about $86,000 \mathrm{sq} \mathrm{km}$ which represent $9.30 \%$ of the total land area of the country. The state is divided into three agricultural zones taking into account the agro climatic features. The State comprises of 25 Local Government Areas. Primary data were collected through field survey from 5 out of 8 Local Government Areas (LGA) in Zone 1 of Niger State Agricultural development Programme (NSADP) where lowland rice is a major crop because of their proximity to the National Cereal Research Institute, whose mandate focuses mainly on rice research.

The LGAs and villages sampled were Katcha (Gbakoggi-kasara and Nwogi), Lavun (Doko and Jima), Gbakko (Gbadafu and Shabafu), Bida (Emi-ndaloke and Fogun-asaga) and Mokwa (wuya-kade and wuya-kpata).

From each of the LGA's, two villages were randomly selected from which one farmers group was randomly selected per village and $80 \%$ of the members of the group were interviewed. From a total of 232 farmers, 186 farmers were interviewed by trained enumerators who understand the local language.

\section{Measurement of variables}

The dependent variable, information needs, was measured by assigning 16 items of information needs equal weight of one point each if needed and 0 if otherwise. The independent variables measured were some socioeconomic profile of the respondents and sources of information. Other independent variables included preferred information package $(1=$ Yes; $0=$ No), preferred communication medium(1=Yes; $0=\mathrm{No})$, readiness to pay for cost of information packaging materials $(1=$ Yes; $0=\mathrm{No})$, preferred information package $(1=$ Yes; $0=\mathrm{No})$ measured at the nominal level. The level of constraint was measured by assigning 8 constraints items equal weight of one point each if regarded as a constraint and 0 if otherwise.

Further more, in the information needs score and constraint score were obtained by adding the score for each respondent and categorized into low and high. The mean information score was 7 and the categories were low (0-7) and high (8-16) while for constraint the mean score obtained was 3 and categorized as low (0-3) and high (4-8).

The data collected from this study were subjected to both descriptive and inferential statistics using the SPSS (11.0) statistical package. Objectives 1 to 4 were analyzed using descriptive statistics such as frequency count, percentages and mean while the 5th objective was achieved by inferential statistics with the use of chi-square.

\section{RESULTS AND DISCUSSION}

\section{Socio-economic characteristics:}

The socioeconomic characteristics of the respondents is presented in Table 1. The Table revealed that majority $(94.4 \%)$ of the respondents were males and above $52 \%$ were middle aged (30-50yrs). The Table also shows that about $27 \%$ had secondary education and $28 \%$ had personal telephone (GSM). 


\section{Literacy level:}

The ability of respondents to read and write in major Nigerian languages is presented in Table 2. About $32 \%$ of the respondents were good in ability to read and write in English and about $15 \%$ were good in Nupe which is a local language. The literacy level will be of use in designing information packages for rice farmers in accordance with the ability to read or write. Farmers who are unable to read or write could be reached more through personal contact.

\section{Type of information needed:}

As for the type of information needed by the respondents, majority (89.8\%) of the farmers need information on crop production as indicated in Table 3. This is understandably due to the fact that they are mainly crop farmers and are probably interested in information that would lead to increased productivity. This is similar to the findings of Wesseler and Brinkman. (2002) that asserted that information needs of farmers are centered around production. About $75 \%$ are interested in information on soil and land management and $67 \%$ interested in information related to agricultural and rural credit.

\section{Preferred communication medium:}

The most important preferred communication medium by the respondents is personal contact $(82.8 \%)$ as shown in Table 4 . None of the respondents mentioned the use of e-mail, FAX, EMS/courier and normal post. This is contrary to the findings of LesaonaTshabalala (2001) which reported that farmers preferred surface mail (normal post). The reason for no farmer reporting the preference for e-mail may be due to the fact that the e-mail require accessibility to the use of internet which they seldom have access and lack computer literacy as reported by Morrow (2002). It could also be due to the fact that e-mail and internet are just beginning to make their make in rural areas (Mundy and Sultan, 2001). The non preference of FAX may be due to the fact that they are not probably even aware of the FAX machine not to talk of the use.

\section{Preferred information packaged:}

With regard to how the farmers preferred information to be packaged, $37 \%$ preferred information to be packaged in audio cassette and $23 \%$ preferred it as extension publication as indicated in Table 5. The reason for higher preference for audio cassette could be due to the fact that it is similar to radio but could be heard over and over again. As for the extension publication preference, it will be of better advantage if it is in the language understood by majority of the farmers

\section{Information sources:}

Majority $(72.7 \%)$ of the rice farmers usually seek information from the extension agents followed by friends/fellow farmers $(26.7 \%)$ as indicated in Table 6 . The high percentage $(72.7 \%)$ of farmers seeking for information from the extension agent. tend to give credence to personal contact as a preferred communication medium as indicated in Table 4 This is in agreement to the findings of other researchers that extension agents are important sources of agricultural information ( Tologbonse and Adekunle, 2000; Tologbonse, 2002) 


\section{Journal of Agricultural Extension}

Vol. 12 (2) December, 2008

\section{Constraints:}

Table 7 shows the distribution of respondents according to nature of constraints they encounter. Major constraints include lack of funds to obtain information $(54.3 \%)$ and language barrier $(50.5 \%)$. Other constraint encountered are outdated information $(36 \%)$ and presentation/poor format of information (33.9\%)

\section{Relationship between variables:}

The result of the Chi-square analysis on Table 7 indicates that there was a significant relationship between information type and the following variables namely, preferred information package $\left(X^{2}=27.96 ; p<0.05\right)$, readiness to pay for information package $\left(X^{2}=67.45 ; p<05\right)$ and constraint $\left(\left(X^{2}=33.28 ; p<05\right)\right.$. The Table also shows that there was no significant relationship between information type and the following variables namely, age $\left(X^{2}=0.001 ; p<05\right)$, educational level $\left(X^{2}=1.59 ; p<05\right)$, sex $\left(X^{2}=1.31 ; p\right.$ $<05$ ) and ownership of telephone $\left(X^{2}=0.48 ; p<05\right)$.

The contingency table revealed that as the information types increases the number of constraint also increases. The higher the information type the higher the number constraints.

\section{CONCLUSION}

This study has shown that some respondents are able to read and write in local Nupe language and as such attempt should be made to provide information in form of publication and radio programme in this language. The literacy level will be of use in designing information packages for farmers in accordance with their ability to read or write in Nupe language. Farmers who are unable to read or write could be reached more through personal contact especially on crop production.

Majority $(89.8 \%)$ of the farmers need information on crop production. This is understandably due to the fact that they are mainly crop farmers and are probably interested in information that would lead to increased productivity.

The high percentage $(72.7 \%)$ of farmers seeking for information from the extension agent tend to give credence to personal contact as a preferred communication medium. With regard to how the farmers preferred information to be packaged, $37 \%$ preferred information to be packaged as audio cassette. Major constraints include lack of funds to acquire information (54.3\%) and language barrier $(50.5 \%)$.

The result of the study also indicates a significant relationship between information type and preferred information package $\left(X^{2}=27.96 ; p<0.05\right)$, readiness to pay for information package $\left(X^{2}=67.45 ; p<05\right)$ and constraint $\left(\left(X^{2}=33.28 ; p<05\right)\right.$. No significant relationship between information type and, age $\left(X^{2}=0.001 ; p<05\right)$, educational level $\left(X^{2}=1.59 ; p<05\right)$, sex $\left(X^{2}=1.31 ; p<05\right)$ and ownership of telephone $\left(X^{2}=0.48 ; p<05\right)$.

The contingency table revealed that as the information types increases the constraint also increases. The higher the information type the more the constraints encountered.

Based on the above it is recommended that, the extension agent be encouraged by intensifying efforts to train and retrain them in aspect of interpersonal skills and effort be made to emphasize and popularize the use of mediated information 
sources and extension research methodology in order to increase the extension coverage area which is likely to increase the farmers assess to needed information.

If the approaches to agricultural development programmes are to give a meaningful result, Nigerian governments in particular and all stakeholders in extension system in the country need to take new approaches to information dissemination and management that grow out from a clear understanding of what farmers information needs are. One sure way of doing this is the inclusion of the NAQAS concept in the agricultural extension policy.

\section{References}

Bembridge, T.J. (1997). Agricultural publications in small-scale farmers extension. South African Journal of Agricultural Extension 26: 1-11.

Carter, I. (1999). Locally generated printed materials in agriculture: Experience from Uganda and Ghana. Education Research Report No. 31. London: Department for International Development (DfID).

Carter, I. (2000). Read all about it: How relevant are printed materials for farmers in Africa? URL: http://www. id21.org/society/4aic1.html [viewed July 17, 2003].

Meyer, H.W.J. and J. A. Boon. (2003). Provision of agricultural information for development: a case study on crossing communication boundaries. Libri 53: 174-78.

Morrow, K., F. Nielsen, and C. Wettasinha, (2002). Changing information flows. LEISA 18(2): 4-5.

Lesaona-Tshabalala, B.V (2001). Agricultural information needs and resources available to agriculturists and farmers in a developing country with special reference to Lesotho. Dissertation submitted in partial fulfillment of the requirements for the degree Master of Information in the department of information studies, Faculty of Arts, Rand Afrikaans University, May 2001. $100 \mathrm{pp}$.

Oguya.V (2007). CTA vision for the Question and Answer Service (QAS). Paper presented at NAQAS stakeholders meeting on strategies to involve farmers' in NAQAS service in Nigeria held at NAERLS/ABU, Zaria. 8pp

Omenesa, Z. E (2007). Assessment of farmers information needs and other beneficiaries through the NAQAS-ICT. Paper presented at NAQAS stakeholders meeting on strategies to involve farmers' in NAQAS service in Nigeria held at NAERLS/ABU, Zaria. 8pp

Ozowa. V.N (1995) Information needs of Small Scale Farmers in Africa: The Nigerian Example. Quarterly Bulletin of the International Association of Agricultural Information Specialists, IAALD/CABI. v. 40, no. 1, 1995.

Tologbonse, E.B and Adekunle. O.A (2000). Adoption of cowpea protection recommendation by rural farmers in Benue State, Nigeria. Journal of Agricultural extension. Vol 4 pp44-55.

Tologbonse, E.B (2002). Practices and Adoption of cowpea protection recommendations by farmers in Federal Capital Territory, Abuja, Nigeria. Journal of Sustainable tropical Agricultural Research. Vol 3: 80-86. 
Journal of Agricultural Extension

Vol. 12 (2) December, 2008

Tripp, R. (2006). Labour, information and Agricultural Technology. In Self-sufficient Agriculture: Labour and Knowledge in small-scale farming . 53-55pp

Wesseler, G and Brinkman. I. W (2002). Bridging information gaps between farmers, policy-makers, researchers and development agents. Paper presented at the regional conference on Agro-forestry impacts on livelihoods in Southern Africa: Putting research into practice. Aventura Warmbath, South Africa, 20-24 May 2002. CTA Working Document Number 8030. 
TABLE 1: Distribution of Respondents According to some socio-economic characteristics $(n=186)^{*}$

\begin{tabular}{|c|c|c|}
\hline Variable & Frequency & $\%$ \\
\hline \multicolumn{3}{|l|}{ Sex } \\
\hline Male & 176 & 94.4 \\
\hline Female & 10 & 5.6 \\
\hline \multicolumn{3}{|l|}{ Age } \\
\hline Young (<30yrs) & 42 & 22.6 \\
\hline middle aged(30-50) & 97 & 52.2 \\
\hline old (51 \& above) & 47 & 25.3 \\
\hline \multicolumn{3}{|l|}{ Educational level } \\
\hline Primary & 17 & 9.1 \\
\hline Secondary & 51 & 27.4 \\
\hline Post secondary & 17 & 9.1 \\
\hline Arabic & 32 & 17.2 \\
\hline Illiterate & 69 & 37.1 \\
\hline \multicolumn{3}{|l|}{ Have telephone? } \\
\hline Yes & 52 & 28 \\
\hline No & 134 & 72 \\
\hline
\end{tabular}

Source: 2007 field survey

TABLE 2: Distribution of Respondents According to literacy levels*

\begin{tabular}{cccc}
\hline Languages & \multicolumn{3}{c}{ Ability to read and write } \\
& none & fair & good \\
\hline English & - & $22(11.8)$ & $60(32.3)$ \\
Hausa & - & $37(19.9)$ & $19(10.2)$ \\
Yoruba & - & $7(3.8)$ & $6(3.2)$ \\
Nupe & & $31(16.7)$ & $28(15.1)$ \\
Arabic & $3(1.6)$ & $6(3.2)$ & $26(14.0)$
\end{tabular}

Figures in parenthesis are \%

*multiple response 
Journal of Agricultural Extension

Vol. 12 (2) December, 2008

TABLE 3: Distribution of Respondents According to Type of Information needed $(n=186)^{*}$

\begin{tabular}{lcc}
\hline \multicolumn{1}{c}{ Area of information needs } & Freq & \% \\
\hline A: Agricultural Production & 167 & 89.8 \\
Crop production & 123 & 66.1 \\
Animal production practices & 81 & 43.5 \\
Crop pest and diseases management & 92 & 49.5 \\
Animal pests and disease management & 20 & 10.8 \\
Agricultural machinery and equipment & $\mathbf{9 7}$ & $\mathbf{5 2 . 0}$ \\
Mean & & \\
B: Environmental protection \& natural resource & & \\
management & 140 & $\mathbf{7 5 . 3}$ \\
Soil and land management & 27 & 14.5 \\
Agro-climatology & 32 & 17.2 \\
Waste management & 37 & 19.9 \\
Forest management & 9 & 4.8 \\
pollution & $\mathbf{4 9}$ & $\mathbf{2 6 . 4}$ \\
Mean & & \\
C: Agricultural marketing and trade & 124 & $\mathbf{6 6 . 7}$ \\
Agricultural \& rural credit, banking \& finance & 41 & 22.0 \\
Enterprise \& agro-industry development & 115 & 61.8 \\
Trade \& marketing of agricultural products & 73 & 39.2 \\
Handling, transport, storage & 98 & 52.7 \\
Processing of agricultural products & 90 & 48.4 \\
Agricultural prices & $\mathbf{9 0}$ & $\mathbf{4 8 . 5}$ \\
Mean & &
\end{tabular}

${ }^{*}$ Multiple responses

Source: field survey, 2007

TABLE 4: Distribution of Respondents According to Preferred communication medium $(n=186)^{*}$

\begin{tabular}{lcc}
\hline \multicolumn{1}{c}{ Communication medium } & Freq & \% \\
\hline Normal post & 0.0 & 0.0 \\
EMS/courier & 0.0 & 0.0 \\
Fax & 0.0 & 0.0 \\
Telephone & 1 & 0.5 \\
E-mail & 0.0 & 0.0 \\
Personal contact & 154 & 82.8 \\
Radio & 31 & 16.7 \\
\hline
\end{tabular}

*Multiple response

Source: field survey, 2007 
TABLE 5: Distribution of Respondents According to preferred Information packaged $(n=185)$

\begin{tabular}{lcc}
\hline \multicolumn{1}{c}{ Information package } & freq & $\%$ \\
\hline \multicolumn{1}{c}{ Extension publications } & 42 & 22.7 \\
Audio cassette & 70 & 37.3 \\
Video cassette & 31 & 16.2 \\
CD-ROM & 23 & 12.4 \\
others & 19 & 10.3 \\
\hline
\end{tabular}

Source: field survey, 2007

TABLE 6: Distribution of Respondents According to sources where they usually seek for Information $(n=180)^{*}$

\begin{tabular}{lcc}
\hline \multicolumn{1}{c}{ sources } & Freq & $\%$ \\
\hline Extension agents & 130 & 72.7 \\
Friends/fellow farmers & 48 & 26.7 \\
Radio & 14 & 7.8 \\
Television & 2 & 1.6 \\
\hline
\end{tabular}

Source: field survey, 2007

TABLE 7: Distribution of Respondents According to Nature of Constraints $(n=186)^{*}$

\begin{tabular}{lcc}
\hline \multicolumn{1}{c}{ Nature of constraints } & Freq & $\%$ \\
\hline 1.Ignorance of information sources & 50 & 26.9 \\
2. Availability of information & 57 & 30.6 \\
3. Reliability of information sources & 57 & 30.6 \\
4.Outdated information & 68 & 36.6 \\
5. language barrier & 94 & 50.5 \\
6. Relevance and usefulness of information & 36 & 19.4 \\
7. Presentation/poor format of information & 63 & 33.9 \\
8. Lack of funds to acquire information & 101 & 54.3 \\
9. others & 1 & 0.5 \\
\hline
\end{tabular}

${ }^{*}$ Multiple Response 
Journal of Agricultural Extension

Vol. 12 (2) December, 2008

TABLE 8: Chi-square and contingency analysis of the relationship between Information type some variables

$$
\text { Variable }
$$

- Preferred information package

- Readiness to pay for information package

- Constraint

- Age

- Ownership of telephone

- Sex

- Educational level

$\begin{array}{cccc}\mathrm{X}^{2} & \begin{array}{c}\text { Degree } \\ \text { of } \\ \text { Freedom } \\ \text { (DF) }\end{array} & \begin{array}{c}\text { Consultanc } \\ \mathrm{y} \\ \text { Coefficient } \\ \text { (CC) }\end{array} & \begin{array}{c}\% \text { Level of } \\ \text { Significanc } \\ \text { e (P) }\end{array} \\ 27.96 & 4 & 0.364 & 0.000 \\ 67.45 & 1 & 0.517 & 0.000 \\ 33.28 & 1 & 0.392 & 0.000 \\ 0.001 & 1 & 0.003 & 0.545 \\ 0.48 & 1 & 0.051 & 0.302 \\ 1.302 & 1 & 0.084 & 0.328 \\ 1.59 & 1 & 0.207 & 0.134\end{array}$

Source: Field survey, 2007 